\title{
Simulations of the 1979-88 polar climates by global climate models
}

\author{
Biao Chen, David H. Bromwich, Keith M. Hines and Xuguang Pan \\ Polar Meteorology Group, Byrd Polar Research Center, The Ohio State University, Columbus, OH 43210, U.S.A.
}

\begin{abstract}
The simulation of the northern and southern polar climates for 197988 by 14 global climate models (GCMs), using the observed monthly averaged sea-surface temperatures and sea-ice extents as boundary conditions, is part of an international effort to determine the systematic errors of atmospheric models under realistic conditions, the so-called Atmospheric Model Intercomparison Project (AMIP). In this study, intercomparison of the models' simulation of polar climate is discussed in terms of selected surface and vertically integrated monthly averaged quantities, such as sea-level pressure, cloudiness, precipitable water, precipitation and evaporation/sublimation. The results suggest that the accuracy of model-simulated climate features in high latitudes primarily depends on the horizontal resolution and the treatment of physical processes in the GCMs. AMIP offers an unprecedented opportunity for the comprehensive evaluation and validation of current atmospheric models and provides valuable information for model improvement.
\end{abstract}

\section{INTRODUCTION}

Intercomparison of the results from different atmospheric model integrations has been underway since the 1950s (Smagorinsky, 1963) and is an important part of modeling research. Most such model intercomparisons have been made in connection with numerical weather prediction (GARP, 1971; NAS, 1975). Fewer evaluations of climate models have been conducted; recent enhanced efforts have been carried out by the Intergovernmental Panel on Climate Change (IPCC) (Gates and others, 1990, 1992) and by the Working Group on Numerical Experimentation (WGNE; Boer and others, 1992). They show that, although there is continuing disagreement among current models and between models and corresponding observations, there has been an overall narrowing of the range of model results and an improvement in the models' systematic errors as a whole.

The simulation of the northern and southern polar climates for 1979-88 by 14 global climate models (GCMs), using the observed monthly averaged seasurface temperatures and sea-ice extents as boundary conditions, is part of an international effort to determine the systematic errors of atmospheric models under realistic conditions, the so-called Atmospheric Model Intercomparison Project (AMIP; Gates, 1992). The basic purposes of AMIP are to undertake the systematic intercomparison and validation of the performance of atmospheric GCMs on seasonal and inter-annual timescales under the most realistic conditions possible and to support in-depth diagnosis and interpretation of the model results. Such analyses and intercomparisons require that all models simulate the same time period under comparable experimental conditions and that the same diagnostic measures of performance be calculated for all models. Table 1 shows the selected characteristics of the atmospheric GCMs included in this paper, such as the resolutions and main parameterization schemes, etc. More complete descriptions of the AMIP models are given by Phillips (1994).

The roles of the polar regions in climate and climate change include being not only the principal heat sinks of the global atmospheric circulation, but also the locations where direct interactions between the atmosphere, ocean and cryosphere take place. Recent studies on the simul-ated climate change due to the doubling of atmospheric $\mathrm{CO}_{2}$ show the high latitudes to be one of the most sensitive regions for changes in variables such as temperature, precipitation, and snow and sea-ice coverage (Mitchell and others, 1990). However, there are shortcomings in present-climate simulations by current climate models, particularly in polar areas (Xu and others, 1990; Tzeng and others, 1993, 1994; Bromwich and others, 1994; Tzeng and Bromwich, 1994). In this study, intercomparison of the models' simulation of the $1979-88$ polar climate is discussed along with the observations in terms of selected surface and vertically integrated monthly averaged quantities, such as sea-level pressure, cloudiness, precipitable water, precipitation and evaporation/sublimation. The results suggest that the models' three-dimensional variables and even the daily outputs for particular models are needed to diagnose governing physical and dynamical processes in the models and to suggest feasible remedies for curing the identified shortcomings.

\section{SEA-LEVEL PRESSURE}

By analyzing the simulated climate of the NCAR CCM 1 over the Arctic at horizontal resolutions of R15 and T42, 
Table 1. Selected characteristics of the atmospheric GCMs included in this paper (after Gates, 1992)

\begin{tabular}{|c|c|c|c|c|c|}
\hline Group/model & $\begin{array}{l}\text { Horizontal } \\
\text { resolution }\end{array}$ & $\begin{array}{l}\text { Vertical } \\
\text { co-ordinate } \\
\text { and level }\end{array}$ & $\begin{array}{l}\text { Convection } \\
\text { scheme }\end{array}$ & Radiation scheme & Cloud scheme \\
\hline BMRC & $\mathrm{R} 31(2.8 \times 3.8)$ & $\sigma 19$ & Kuo & $\begin{array}{l}\text { Lacis-Hansen, } \\
\text { Fels-Schwarzkopf }\end{array}$ & Slingo, Rikus \\
\hline CCC/GCMII & $\mathrm{T} 32(3.8 \times 3.8)$ & Hybrid 10 & MCA & $\begin{array}{l}\text { Fouquart-Bonnel, } \\
\text { Morcrette and others }\end{array}$ & $\begin{array}{l}\text { McFarlane and } \\
\text { others }\end{array}$ \\
\hline CSIRO & $\mathrm{R} 21(3.2 \times 5.6)$ & $\sigma 19$ & MCA & Fels-Schwarzkopf & Gordon-Hunt \\
\hline CSU & $4 \times 5$ & Modified $\sigma 17$ & $\mathrm{~A}-\mathrm{S}$ & Harshvardhan and others & Randall \\
\hline DNM & $4 \times 5$ & $\sigma 7$ & Kuo & $\begin{array}{l}\text { Manabe-Strickler, } \\
\text { Lacis-Hansen, Feigelson }\end{array}$ & Slingo \\
\hline ECMWF/Cy36 & $\mathrm{T} 42(2.8 \times 2.8)$ & Hybrid 19 & Tiedtke & Morcrette & Smagorinsky \\
\hline GFDL & $\mathrm{T} 42(2.8 \times 2.8)$ & $\sigma 18$ & MCA & $\begin{array}{l}\text { Lacis-Hansen, } \\
\text { Rodgers-Walshaw }\end{array}$ & $\begin{array}{l}\text { Wetherald-- } \\
\text { Manabe }\end{array}$ \\
\hline GLA/Version 8 & $4 \times 5$ & $\sigma 17$ & $\mathrm{~A}-\mathrm{S}$ & $\begin{array}{l}\text { Lacis-Hansen, } \\
\text { Harshvardhan-Corsetti }\end{array}$ & Slingo \\
\hline GSFC & $4 \times 5$ & $\sigma 17$ & $\begin{array}{l}\text { Moorthi- } \\
\text { Suarez }\end{array}$ & Harshvardhan & $\begin{array}{l}\text { Convective and } \\
\text { large-scale }\end{array}$ \\
\hline MPI/ECHAM & $\mathrm{T} 42(2.8 \times 2.8)$ & Hybrid 19 & Tiedtke & $\begin{array}{l}\text { Hense and others, } \\
\text { Rockel and others }\end{array}$ & Sundqvist \\
\hline MRI & $4 \times 5$ & Hybrid 15 & $\mathrm{~A}-\mathrm{S}$ & Lacis-Hansen, Shibata-Aoki & Tokioka and others \\
\hline NMC/MRF & $\mathrm{T} 40(3 \times 3)$ & $\sigma 18$ & Kuo & $\begin{array}{l}\text { Lacis-Hansen, } \\
\text { Fels-Schwarzkopf }\end{array}$ & Slingo \\
\hline SUNYA/CCMl & $\operatorname{R} 15(4.5 \times 7.5)$ & $\sigma 12$ & MCA & $\begin{array}{l}\text { Kiehl and others, } \\
\text { Wang and others }\end{array}$ & Kiehl and others \\
\hline
\end{tabular}

$\mathrm{R}=$ rhomboidal spectral truncation; $\mathrm{T}=$ triangular spectral truncation; $n \times m, n={ }^{\circ}$ latitude, $m={ }^{\circ}$ longitude.

$\mathrm{A}-\mathrm{S}=$ Arakawa-Schubert; $\mathrm{MCA}=$ moist convective adjustment.

BMRC $=$ Bureau of Meteorology Research Centre, Melbourne, Australia; CCC = Canadian Climate Centre, Downsview, Ontario; CSIRO = Commonwealth Scientific and Industrial Research Organization, Mordialloc, Australia; CSU = Colorado State University, Fort Collins, Colorado; DNM = Department of Numerical Math-ematics, Russian Academy of Sciences, Moscow; ECMWF = European Centre for MediumRange Weather Forecasts, Reading, England; GFDL = Geophysical Fluid Dynamics Laboratory, Princeton, New Jersey; GLA = Goddard Laboratory for Atmospheres, Greenbelt, Maryland; GSFC = Goddard Space Flight Center, Greenbelt, Maryland; MPI = Max Planck Institute for Meteorology, Hamburg, Germany; MRI = Meteorological Research Institute, Tsukuba, Japan; NMC = National Meteorological Center, Washington D.C.; SUNYA = State University of New York, Albany.

Bromwich and others (1994) found in the lowerresolution version of CCMl that the topography of Greenland was distorted and that this resulted in a major dislocation of the simulated North Atlantic storm track. They pointed out that this bias was substantially alleviated when the horizontal resolution increased to T42. The European Centre for Medium-Range Weather Forecasts' (ECMWF) analyses, averaged over a 10 year period (1980-89) from NCAR, were used for the observations of sea-level pressure. The zonally averaged sea-level pressure from the simulations and observations for DJF and JJA is given in Figure 1. The simulated results in Figure la and $\mathrm{b}$ for the higher-resolution models are clearly much better than those in Figure $1 \mathrm{c}$ and $\mathrm{d}$ that present the lower-resolution model results. This suggests that the horizontal resolution of a model is one of the major factors determining the accuracy of the simulated climatological mass field in high latitudes as well as other regions. A similar result has also been found by Boer and others (1992). The biases in Arctic latitudes are slightly smaller than over Antarctica in both DJF and JJA. For the lower-resolution models (less than R21), there are significant errors in intensity and spatial phase (Fig. 1c and d). Since the largest predicted uncertainties occur near Antarctica during winter rather than in the Arctic, the primary cause might be insufficient horizontal resolution to handle the complex terrain of Antarctica (Tzeng and others, 1993, 1994).

Because zonally averaged analyses yield only part of the story, a high-horizontal-resolution model (ECMWFT42, 19 levels) and a low-resolution model (CSU $4^{\circ} \times 5^{\circ}, 17$ levels) have been selected to examine the twodimensional simulated sea-level-pressure field during the Arctic winter. Figure 2 shows the differences of sea-level pressure between the high-resolution ECMWF model and the ECMWF analyses for DJF. The errors for the ECMWF model range from $-11 \mathrm{hPa}$ east of the Icelandic low to $+13 \mathrm{hPa}$ southeast of the Aleutian low; this feature is very similar to the error pattern exhibited by the NCAR CCM2 (Tzeng and Bromwich, 1994). The errors for the low-resolution CSU model (not shown) vary from $-29 \mathrm{hPa}$ southeast of the Icelandic low to $+14 \mathrm{hPa}$ over the Arctic Ocean, i.e. the error magnitudes are roughly $80 \%$ larger than those in the ECMWF model. The simulated sea-level pressure for the ECMWF model demonstrates that the model well simulates the weak 


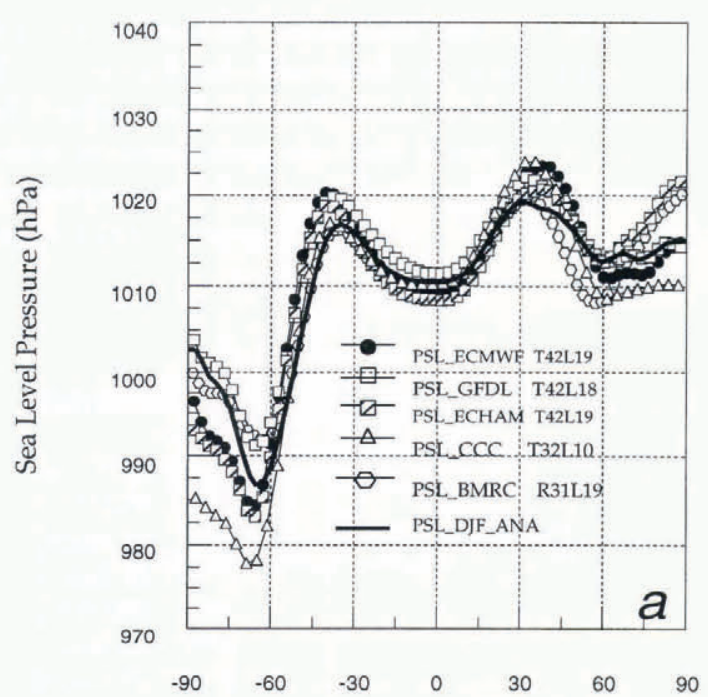

Latitude

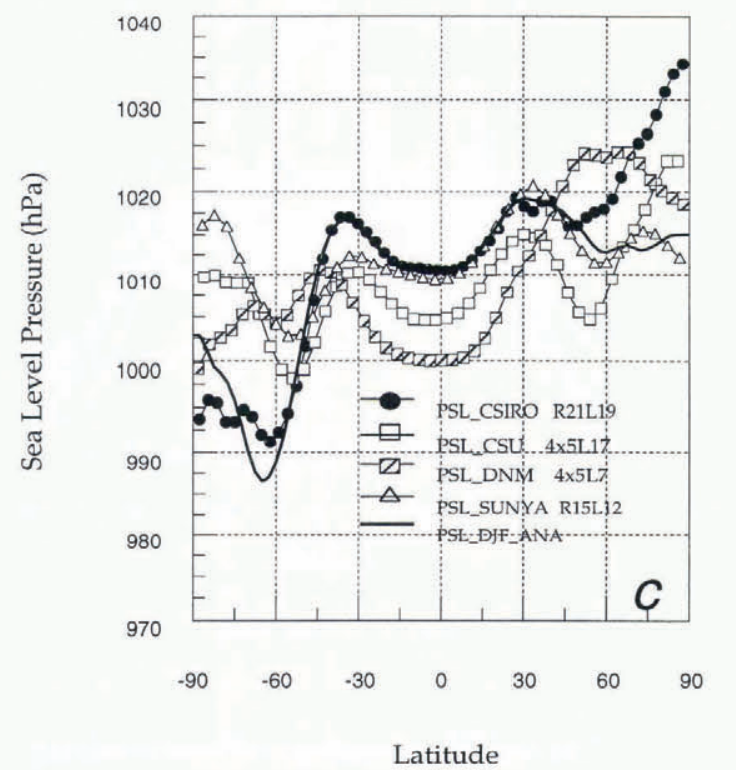

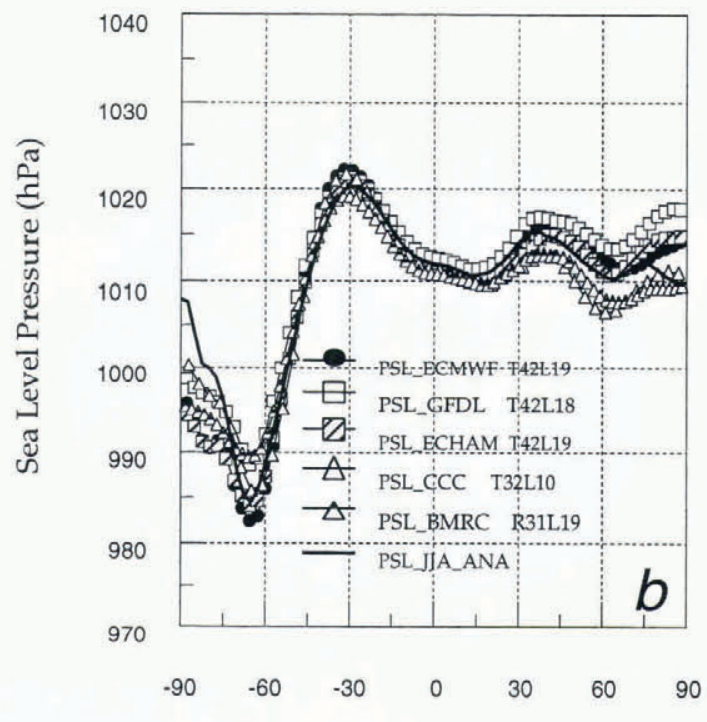

Latitude

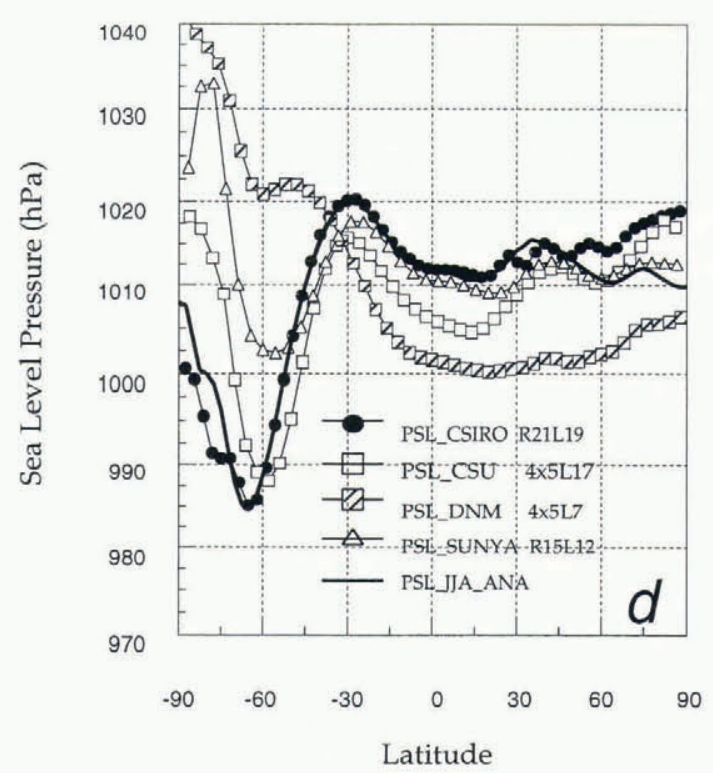

Fig. 1. Zonally averaged simulated and observed (solid lines) sea-level pressure for 10 a averages. a. Higher-horizontalresolution models for D JF. b. Higher-horizontal-resolution models for $7 \mathcal{J} A$. c. Lower-horizontal-resolution models for $D \mathcal{F F}$. d. Lower-horizontal-resolution models for $\mathcal{J} \mathcal{F A}$. The legend text inside the graphs gives model names and resolutions; e.g. T42L19 means horizontal triangular truncation at 42 waves and 19 levels in the vertical; R31L.19 means horizontal rhomboidal truncation at 31 waves and 19 levels in the vertical; and $4 \times 5$ L17 means horizontal resolution of $4^{\circ}$ longitude $\times 5^{\circ}$ latitude and 17 levels in the vertical.

ridges over the Arctic Ocean and the west coast of North America in terms of strength and location. The large ECMWF model's biases south of the Aleutian low and east of the Icelandic low are due, respectively, to an oversimulated and westward-shifted subtropical high over the eastern Pacific Ocean and an eastward elongation of the Icelandic low. By contrast, the simulation by the CSU model illustrates that the errors of the Icelandic low and the ridge over Arctic Ocean result from, respectively, shifting the low center to the southeast of its observed location and misplacing part of the Siberian anticyclone over the Arctic Ocean; however, the simulated Aleutian low agrees well with the observations. It is interesting to note that if a model can well simulate sea-level pressure over the northeastern Pacific and North America larger simulated biases will occur in the Atlantic and Eurasia or vice versa. This phenomenon is also found in the simulations by other models. Although the association of simulated error patterns may be explained by the two major storm tracks, or waveguides, in the Northern Hemisphere, this anti-correlated linkage between the two bias patterns in models is not well understood yet.

\section{PRECIPITATION AND EVAPORATION}

Precipitation and evaporation/sublimation are interesting because they are related to water mass balance, and the accumulation (net precipitation) of ice and snow greatly affects the short-wave solar radiation and the 


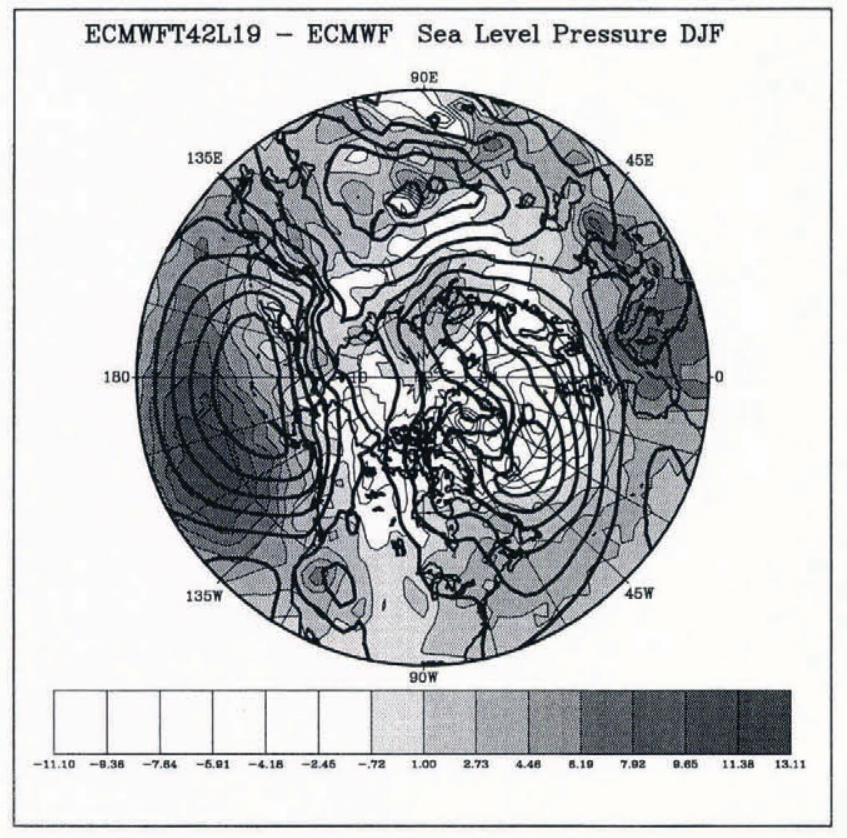

Fig. 2. Sea-level pressure of the ECMWF analyses, shown by the bold contour lines at $5 \mathrm{hPa}$ intervals. The difference of the ECMWF model (higher horizontal resolution T42) minus ECMWF analyses for D fF over the Arctic is masked in gray scale; the scale in $\mathrm{hPa}$ is given at the bottom.

Annual Precipitation (12 models)

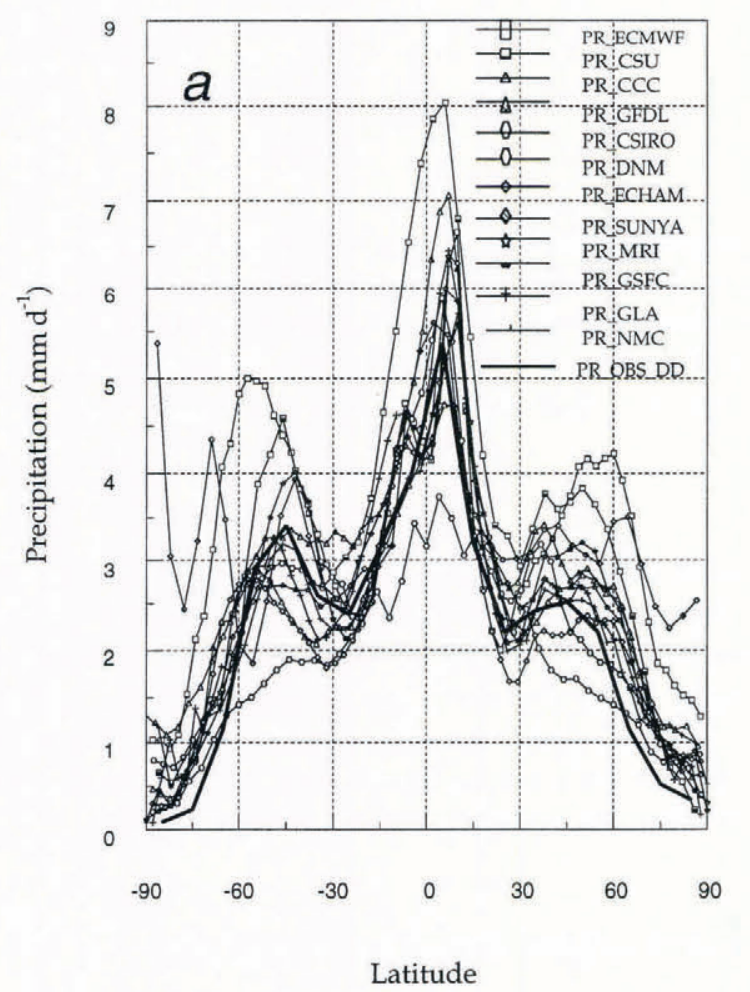

Fig. 3. Zonally averaged annual precipitation in models and observations (solid line). a. All available models. $b$. Best five models. c. Other seven models. long-wave terrestrial radiation. Zonally averaged annual precipit-ation is displayed in Figure 3. The observed data used here come from Sellers (1965). Boer and others (1992) found that the precipitation simulations do not depend strongly on horizontal resolution, unlike the simulated sea-level pressure. Most models

Annual Precipitation (good models)

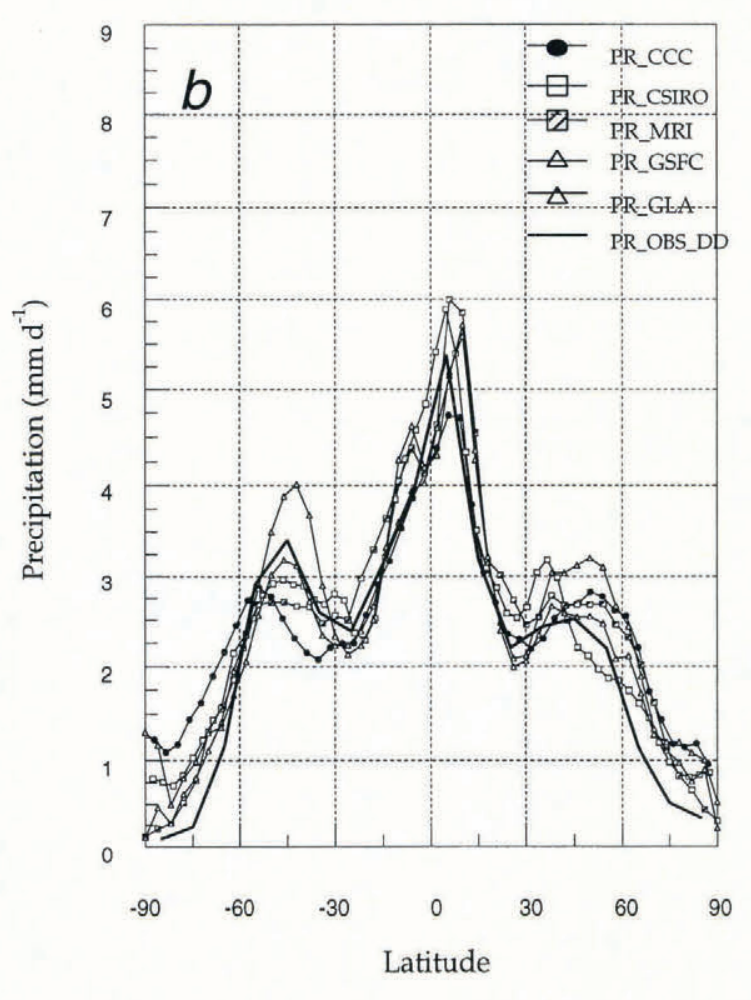

Annual Precipitation (other models)

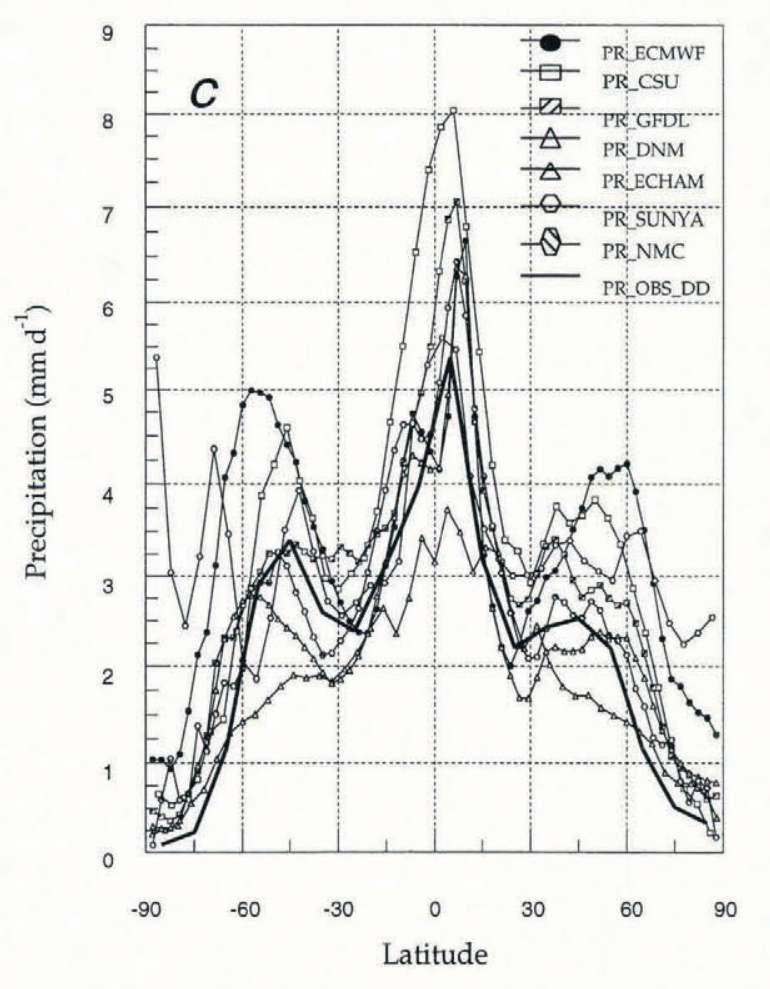


over-simulate precipitation in the tropics and polar areas of both hemispheres and in the mid-latitudes of the Northern Hemisphere. The model results for the southern mid-latitudes vary around the observations. There are uncertainties in the observed data, however, especially over the tropical oceans and the Southern Hemisphere. Figure $3 \mathrm{~b}$ and $\mathrm{c}$ show dramatically different biases of modeled precipitation. The biases for the best five models average about $0.5 \mathrm{~mm} \mathrm{~d}^{-1}$, while the biases for the other group vary from $0.2 \mathrm{~mm} \mathrm{~d}^{-1}$ in the polar regions to $2.0 \mathrm{~mm} \mathrm{~d}^{-1}$ in the tropics. We found that either moist convective adjustment (MCA) or Arakawa-Schubert (A-S) convective schemes are used in the models with small precipitation biases. There are at least five types of convective schemes, including MCA and $\mathrm{A}-\mathrm{S}$ schemes, used in the models with relatively large precipitation biases, indicating that factors additional to the particular convective scheme utilized are involved. Simulated precipitable water values are compared with observations (Peixoto and Oort, 1983) in Figure 4. There are maximum discrepancies in the tropics with secondary deviation maxima over the Arctic and Antarctica. Since most models underestimate precipitable water over Antarctica, yet the simulated precipitable-water values are spread around the observations over the Arctic, the excess simulated precipitation in high latitudes must be due to factors other than moisture availability, such as the general circulations of the respective models and the positivemoisture-fixer scheme in the models with the moisture predicted by the spectral-transform method (Tzeng and others, 1993; Bromwich and others, 1994). In order to draw more solid conclusions on this matter, in-depth diagnosis of the moisture budget will be done for selected models.

Due to the limitations of the modeling data available for evaporation/sublimation, we are only able to analyze output from four models for net precipitation $(P-E)$. Figure 5 shows the simulated precipitation, evaporation/sublimation and net precipitation along with observed convergence of the vertically integrated atmospheric water-vapor flux (Peixoto and Oort, 1992), which is equal to $P-E$. These four models over-simulate precipitation everywhere by $0.4-1.0 \mathrm{mmd}^{-1}$ except for the southern midlatitudes, and overestimate the evaporation rate over the low latitudes and northern mid-latitudes by 0.5 $1 \mathrm{~mm} \mathrm{~d}^{-1}$ but capture the evaporation/sublimation rate quite well over the Arctic and Antarctica in terms of absolute error. The net precipitation, estimated as the difference between precipitation and evaporation/ sublimation, shows that the largest errors occur in high latitudes (especially the Arctic) and net watervapor input to the subtropical atmosphere is significantly oversimulated. The DJF and JJA net precipitation rates $(P-E)$ (Figure omitted) are able to capture the basic zonally averaged features in the observed $(P-E)$. However, all four models overestimate this quantity in the middle and high latitudes of each hemisphere, probably due to the anomalously large simulated precipitation rates.

\section{GLOUD COVERAGE}

Cloud simulation is probably one of the most challenging tasks for atmospheric-climate modeling. Figure 6 shows the total cloudiness estimated by those four models out of the 13 that had passed AMIP quality controls for cloudiness at the time this paper was prepared, along with observations (Peixoto and Oort, 1992) for DJF and JJA. The huge estimated discrepancies in the models range from $20-30 \%$ in low latitudes to $60 \%$ in high latitudes. This may be partially due to the differences in

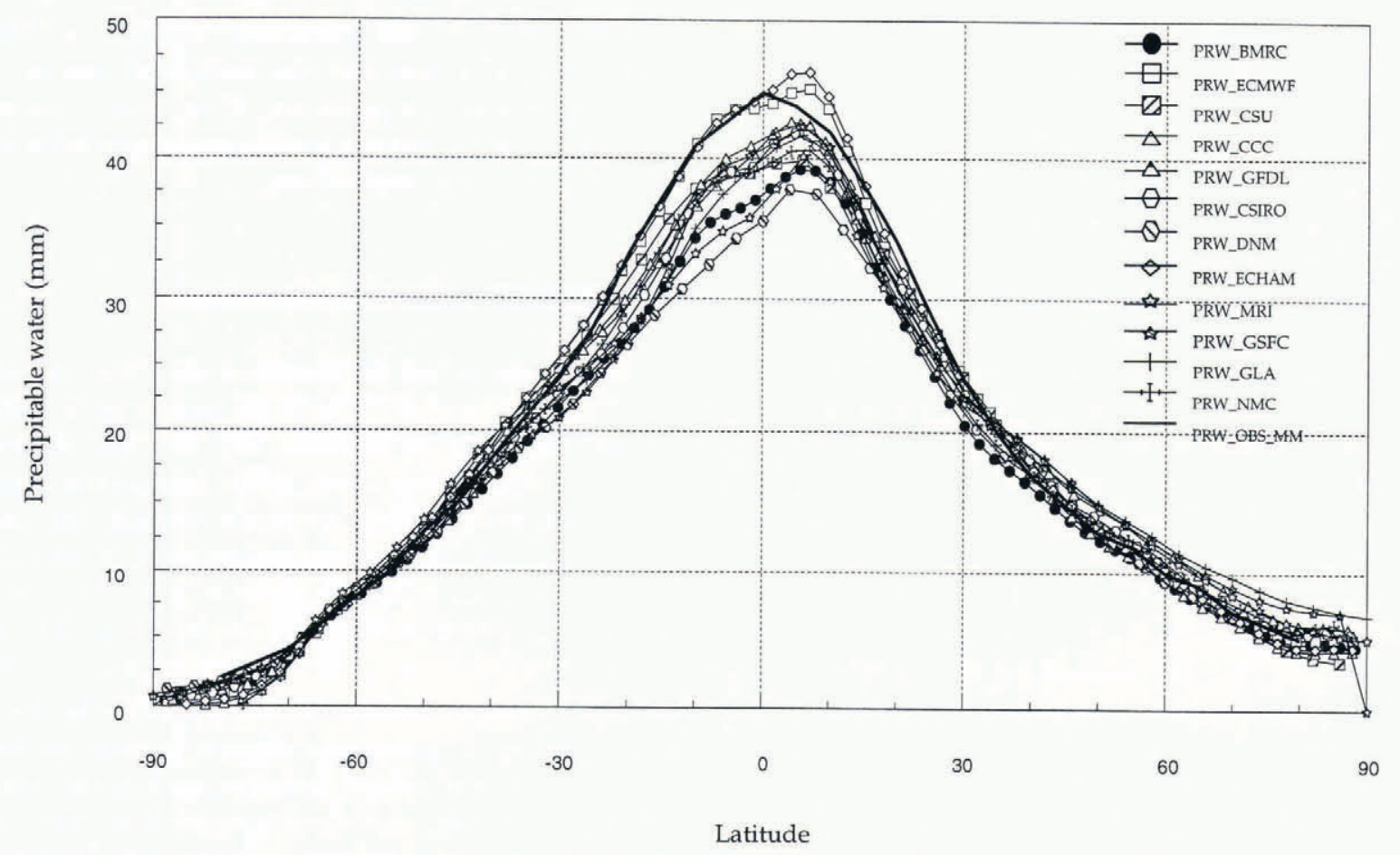

Fig. 4. Zonally averaged annual precipitable water values from models and observations (solid line). 
Annual Precipitation

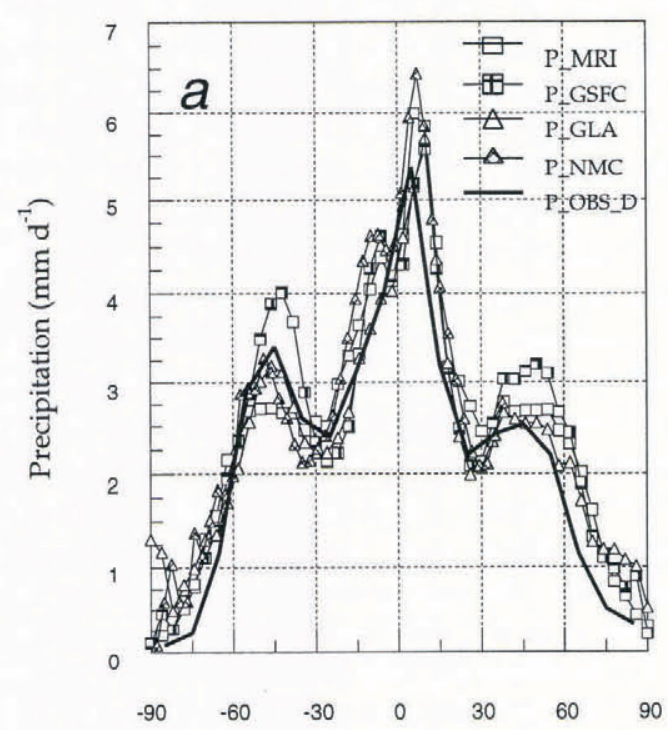

Latitude

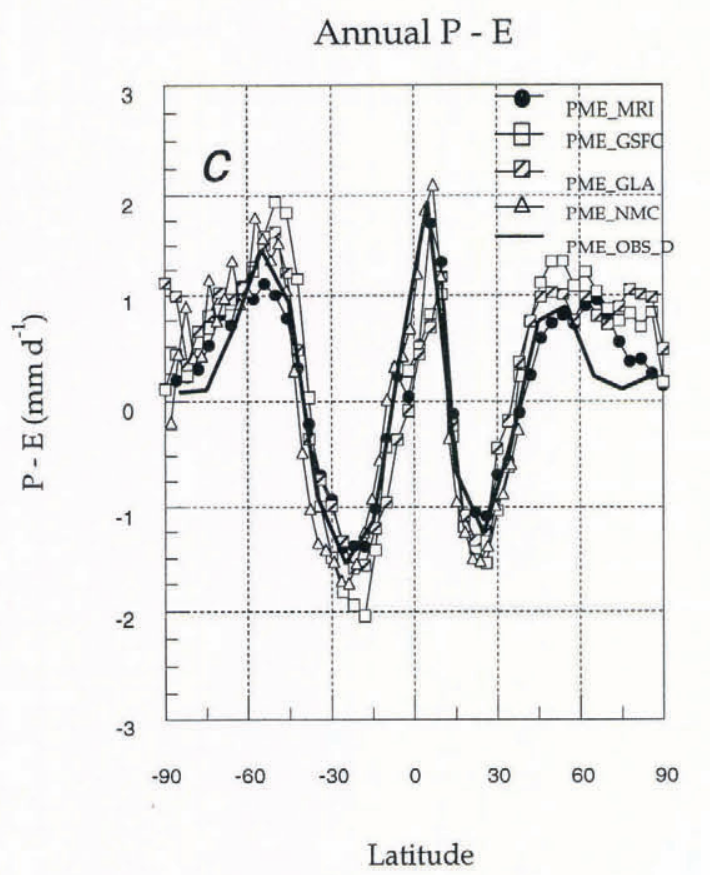

cloud definitions from model to model and between model and observations ( $\mathrm{Li}$ and Letreut, 1989), although the simulated cloud-coverage pattern generally matches the observations in low and middle latitudes. The different definition of large-scale cloud formation among the models could cause a systematic bias in simulated cloudiness over the high latitudes. For instance, in the MRI model, largescale cloud condensation is present and covers the total grid box if the local relative humidity of a layer is at least $100 \%$. In the GLA model, however, only $80 \%$ of a grid box is assumed to be filled by cloud when there is local supersaturation. These different definitions of the cloud formation may result in the overestimated cloudiness in the MRI and the underestimated cloudiness in the GLA. In addition, most models are unable to capture the large seasonal variation of cloudiness over the Arctic. The estimated cloudiness from each model over the Arctic has essentially the same pattern in both DJF and JJA, while the observed cloudiness over the Arctic increases with
Annual Evaporation

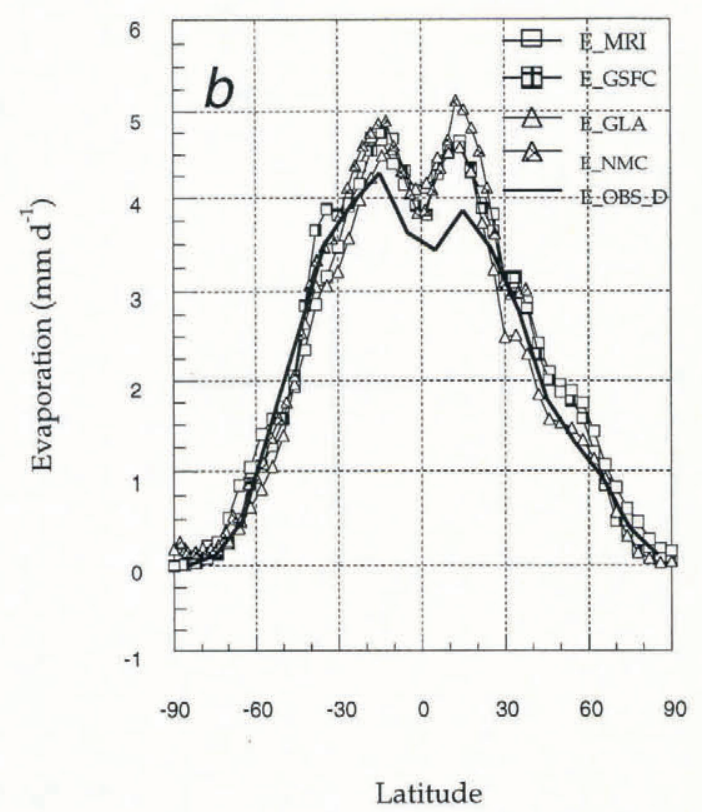

Fig. 5. a. Zonally averaged annual precipitation for four models compared to observations (solid line). b. As in (a), but for evaporation/sublimation. $c$. As in (a), but for net precipitation $(P-E)$.

latitude during summer due to the formation of stratus clouds (Bromwich and others, 1994) and decreases with latitude in winter. It is clear that cloud simulations in the various GCMs are far from satisfactory, which suggests that Arctic climate-change studies based on GCMs should be interpreted very cautiously.

A useful indication of cloud cover can be obtained from the outgoing long-wave radiation at the top of the atmosphere (OLR) and from the planetary albedo. However, the ability of a model to simulate the OLR and planetary albedo depends not only on the algorithms used to compute the radiative transfers within the atmosphere, but also on the simulated clouds, snow cover and surface temperatures. Thus, more comprehensive analyses of the climate models are required for further evaluation of cloud simulations.

\section{DISGUSSION AND CONGLUSION}

Intercomparisons are performed of simulated Arctic and Antarctic climate for $1979-88$ by 14 currently available international-climate models. The research focuses on selected surface and vertically integrated monthly averaged quantities. The accuracy of modeling sea-level pressure depends on horizontal resolution. It seems that a critical resolution exists at about $4^{\circ} \times 4^{\circ}$, i.e. simulated results are significantly improved when the model resolution is better than the critical resolution. Most of the higher-resolution models well capture the locations and intensities of prominent climate features in the sealevel pressure field at high latitudes, such as the Antarctic circumpolar trough and the atmospheric-activity centers at middle and high northern latitudes (e.g. Aleutian low, Icelandic low, Siberian high). In general, the biases in the 


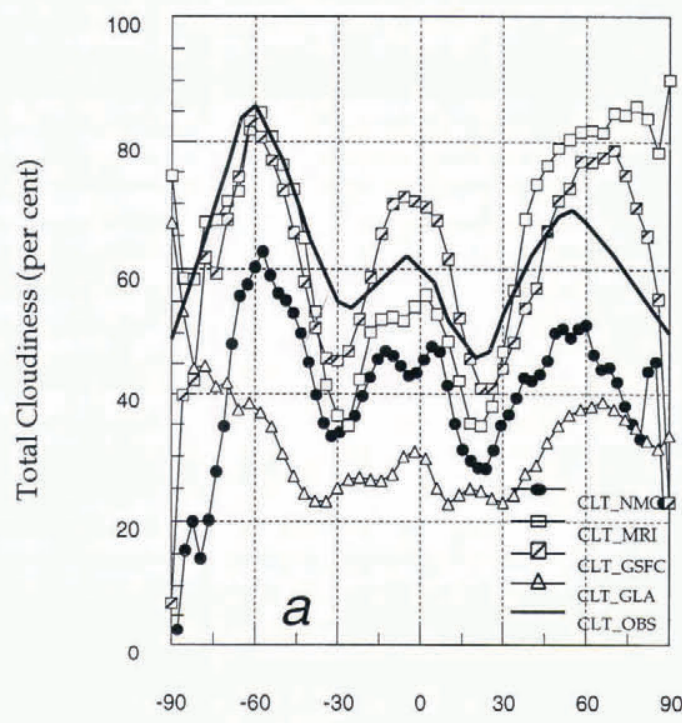

Latitude

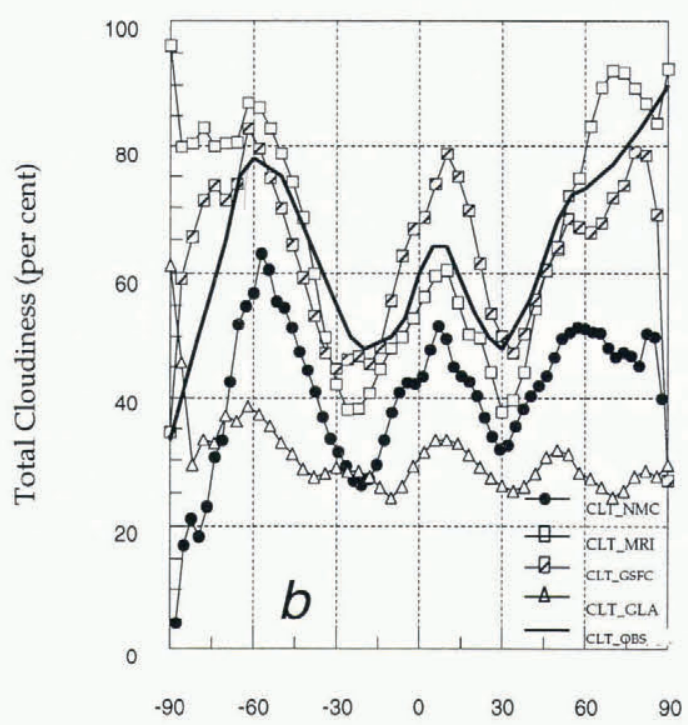

Latitude

Fig. 6. Zonally averaged simulated and observed (solid line) cloudiness (a) for D JF, (b) for JJA.

simulated sea-level pressure are larger in high latitudes than in middle and low latitudes.

The huge errors in the simulated circulations in polar regions will apparently influence many modeled variables in those areas, such as precipitation (Tzeng and others, 1993, 1994; Bromwich and others, 1994; Tzeng and Bromwich, 1994). There is a secondary maximum discrepancy in simulated precipitation over the Arctic and Antarctica besides the maximum biases in the tropics. Since most models underestimate precipitable water over Antarctica yet the simulated precipitable water values are spread around the observations over the Arctic, the cause of the excess simulated precipitation in high latitudes must be factors other than moisture availability, most likely the simulated general circulations of the respective models and the positive-moisture-fixer scheme in models where the moisture is predicted by the spectral-transform method. Most of the models capture the evaporation/ sublimation rate quite well over the polar regions in terms of absolute values. Thus the large errors in the net precipitation over high latitudes, estimated as the difference between precipitation and evaporation/sublimation, are probably caused by the anomalously large simulated precipitation rates.

Relatively poor estimation of precipitation in the polar regions may be partially explained by errors in cloud simulation. The total cloudiness simulated in various models is far from satisfactory in general and even worse in the Arctic. The huge estimated discrepancies in the models range from $50 \%$ to $65 \%$ in high latitudes, which may partially be caused by varying definitions of cloud formation in the models. All models fail to simulate the large seasonal variation of cloudiness over the Arctic. In other words, the cloudiness estimated by each model over the Arctic has essentially the same pattern throughout the year. By contrast, the observed cloudiness over the Arctic increases with latitude during summertime due to the formation of stratus clouds, and decreases with latitude in winter.

\section{ACKNOWLEDGEMENTS}

This work was supported by NSF Grant OPP9224184, by NASA grant NAGW2718 and by the AMIP Diagnostic Subproject on Polar Phenomena and Sea Ice. Preliminary model results were provided by the Program for Climate Model Diagnosis and Intercomparison at Lawrence Livermore National Laboratory, University of California. Additional computations were performed on the CRAY Y-MP of the U.S. National Center for Atmospheric Research and on the CRAY Y-MP of the Ohio Supercomputer Center, which is supported by the State of Ohio. The CPU time on the NCAR CRAY YMP was provided by CRAY Research, Inc. This is contribution No. 924 of Byrd Polar Research Center, The Ohio State University.

\section{REFERENGES}

Boer, G.J. and 13 olhers. 1992. Some results from an intercomparison of the climate simulated by 14 atmospheric general circulation models. 7. Geophys. Res., 97 D12), 12,771-12,786.

Bromwich, D. H., R. -Y. Tzeng and T.R. Parish. 1994. Simulation of the modern Arctic climate by the NCAR CCMl. f. Climate, 7 7), 10501069.

GARP Working Group on Numerical Experiment. 1971. Garcia. R. V.. ed. Report of International Symposium on Spectral Methods in Numerical Weather Prediction. Report No. 7. Geneva, International Council of Scientific Unions and World Meteorological Organization. Global Atmospheric Research Programme.

Gates, W. L. 1992. AMIP. The Atmospheric Model Intercomparison Project. Bull. Am. Meteorol. Soc., 73, 1962-1970.

Gates, W. L., P. R. Rowntree and Q. -C. Zeng. 1990. Validation of climate models. In Houghton, J. T., G. J. Jenkins and J. J. Ephraums, eds. Climate change: the IPCC scientific assessment. Cambridge, Cambridge University Press, 93-130.

Gates, W. L., J.F.B. Mitchell, G.J. Boer, U. Cubasch and V.P. Meleshko. 1992. Climate modelling, climate prediction and model validation. In Houghton, J. T., B. A. Callander and S. K. Varney, eds. Climate change: the supplementary report to the IPCC scientific assessment. 
Cambridge, Cambridge University Press, 97-134.

Li, Z. -X. and H. Letreut. 1989. Comparison of GCM results with data from operational meteorological satellites. Ocean-Air Interactions, 1, 221-237.

Mitchell, J.F.B., S. Manabe, T. Tokioka and V. Meleshko. 1990. Equilibrium climate change. In Houghton, J. T., G.J. Jenkins and J.J. Ephraums, eds. Climate change: the IPCC scientific assessment. Cambridge, Cambridge University Press, 131-172.

National Academy of Sciences (NAS). 1975. Survey of the climate simulation capability of global circulation models. In Understanding climatic change. Washington, DC, National Academy of Sciences, 196239.

Peixoto, J.P. and A.H. Oort. 1983. The atmospheric branch of the hydrological cycle and climate. In Street-Perrott, A., M. Beran and R. Ratcliffe, eds. Variations in the global water budget. Dordrecht, etc., D. Reidel Publishing Company, 5-66.

Peixoto, J.P. and A.H. Oort. 1992. Physics of climate. New York, American Institute of Physics.

Phillips, T.J. 1994. A summary documentation of the AMIP models. Program for climate model diagnosis and intercomparison. Report No. 18. Livermore, CA, University of California. Lawrence Livermore National Laboratory.

Sellers, W. D. 1965. Physical climatology, Chicago, University of Chicago. Smagorinsky, J. 1963. General circulation experiments with the primitive equations. Mon. Weather Rev., 91, 99-164.

Tzeng, R. -Y. and D. H. Bromwich. 1994. NCAR CCM2 simulation of present-day Arctic climate. In Sixth Conference on Climate Variations. Boston, American Meteorological Society, 197-201.

Tzeng, R.-Y., D. H. Bromwich and T.R. Parish. 1993. Present-day Antarctic climatology of the NCAR community climate model version 1. J. Climate, 6, 205-226.

Tzeng, R. -Y., D. H. Bromwich, T. R. Parish and B. Chen. 1994. NCAR CCM2 simulation of the modern Antarctic climate. 7. Geophys. Res., 99(D11), 23,131-23,148.

Xu, J.-S., H. von Storch and H. van Loon. 1990. The performance of four spectral GCMs in the Southern Hemisphere: the January and July climatology and the semiannual waves. F. Climate, 3, 53-70 